\title{
The Relationship between Restrained Eating, Body Image, and Dietary Intake among University Students in China: A Cross-Sectional Study
}

\author{
Cuiting Yong, Hanmei Liu, Qiping Yang (D), Jing Luo, Yufeng Ouyang, Minghui Sun, Yue Xi (D), Caihong Xiang \\ and Qian Lin*D
}

check for updates

Citation: Yong, C.; Liu, H.; Yang, Q.; Luo, J.; Ouyang, Y.; Sun, M.; Xi, Y.; Xiang, C.; Lin, Q. The Relationship between Restrained Eating, Body Image, and Dietary Intake among University Students in China: A Cross-Sectional Study. Nutrients 2021, 13, 990. https://doi.org/ $10.3390 /$ nu13030990

Academic Editor: George Moschonis

Received: 18 February 2021

Accepted: 16 March 2021

Published: 19 March 2021

Publisher's Note: MDPI stays neutral with regard to jurisdictional claims in published maps and institutional affiliations.

Copyright: (c) 2021 by the authors. Licensee MDPI, Basel, Switzerland. This article is an open access article distributed under the terms and conditions of the Creative Commons Attribution (CC BY) license (https:// creativecommons.org/licenses/by/ $4.0 /)$.
Department of Nutrition Science and Food Hygiene, Xiangya School of Public Health, Central South University, 110 Xiangya Rd, Changsha 410078, China; yongcuiting@csu.edu.cn (C.Y.); hanmeiliu@csu.edu.cn (H.L.); yangqiping12@csu.edu.cn (Q.Y.); luojing2546@csu.edu.cn (J.L.); oyyf0102@csu.edu.cn (Y.O.); sun.1234@csu.edu.cn (M.S.); xiyue0404@csu.edu.cn (Y.X.); xch0622@csu.edu.cn (C.X.)

* Correspondence: linqian@csu.edu.cn; Tel.: +86-1387-482-0173

\begin{abstract}
This study aims to explore the association between restrained eating, body image, and dietary intake among Chinese college students. This cross-sectional study included 1301 college students at two universities in Hunan Province. Electronic questionnaires were used to collect information including students' demographic characteristics, restrained eating, perception of body weight, body satisfaction, and dietary intake. Anthropometric measurements were collected to calculate body mass index (BMI). The prevalence of high restrained eating was $52.8 \%$. Students who were dissatisfied with their bodies or overestimated their body weight showed a higher tendency toward high restrained eating $(p<0.05)$. Students with high restrained eating tended to eat fruits and eggs more frequently, while the frequency of eating domestic animals and poultry, sugar-sweetened beverages, and fast food were the opposite. Moreover, high restrained eating was a risk factor for low dietary diversity (odds ratio $(\mathrm{OR})=1.384,95 \%$ confidence interval: $1.002 \sim 1.912$ ). The high incidence of restrained eating among Chinese college students and its energy-restricted diets that may lead to possible health implications require attention. Further studies are needed to investigate the characteristics of college students' restrained eating to tailor appropriate interventions for forming positive body images and promoting healthy eating behaviors, thus, improving dietary quality.
\end{abstract}

Keywords: restrained eating; body image; body dissatisfaction; dietary intake; dietary diversity scores

\section{Introduction}

The concept of restrained eating was first presented by Herman in 1975 and defined as the tendency to restrict food intake to control weight [1]. The study of restrained eating has continuously progressed over time and led to a more comprehensive understanding. Taken together, it has several characteristics: (1) the purpose is to control weight, which includes two aspects-maintaining and losing weight; (2) the restriction behavior is characterized by cognitive and long-term features; (3) restrained eaters pay more attention to extrinsic food cues instead of intrinsic biological cues; and (4) it is more common in young women [2].

Studies show that restrained eating can predict the severity of eating disorders and is a key factor in their development $[3,4]$. On one hand, restrained eaters tend to reduce energy intake to maintain or lose weight [5], which makes them prefer low-calorie food, such as vegetables or fruits, and restrict high-calorie food intake, such as cereals and tubers or domestic animals and poultry [6]. Therefore, over-restrained eating may lead to inadequate energy intake. On the other hand, restrained eaters are more likely to overeat on some occasions, which is called the disinhibition effect, causing a range of eating disorder symptoms (e.g., bulimia nervosa, binge eating) [7]. Moreover, restrained 
eating is accompanied by recurrent and prolonged dieting and overeating, which brings negative emotions (e.g., depression, anxiety, and stress), severely impacting physical and psychosocial health $[8,9]$.

College freshmen comprise an important group undergoing emerging adulthood in a critical period of life during which eating behavior and food preferences are changing and being gradually established, often persisting over time [10]. They have just begun a new journey, facing a richer dietary environment with more options of food. If not properly guided, new students are vulnerable to negative emotionality and external environmental changes; therefore, they are prone to developing poor eating habits and have an increased risk of eating disorders [11]. Some studies have indicated that college students have high restrained eating levels [11-13]. The study of restrained eating among Chinese college students is limited. By the end of 2019, there were more than 42 million enrolled college students in China. Hence, investigating restrained eating and dietary intake in Chinese college students is of eminent importance for the risk assessment of eating disorders.

Some studies have shown that body dissatisfaction or misperception of body weight is an important cause of restrained eating [14-18]. This may be related to the social norm that thinness is considered a mark of beauty, which may influence one's attitudes and behaviors $[19,20]$. College students are in a critical period of aesthetic formation and are vulnerable to external influences. Studies have shown that the incidence of dissatisfaction with students' body image and misperceptions of body weight are both at high levels [12,16]. However, only one study has discussed the moderating effect of body dissatisfaction on the relationship between BMI and dietary restriction among Chinese college students [14]. This research used self-reported weight and height, and did not discuss restrained eating by different body dissatisfaction levels. Therefore, the purpose of our study is to investigate the level of restrained eating among Chinese college students through the Three-Factor Eating Questionnaire, determine the incidence of misperception of body weight and body dissatisfaction, and analyze the relationship between restrained eating and body image.

\section{Materials and Methods}

\subsection{Ethical Approval}

The study was approved by the Ethics Committee of Xiangya School of Public Health, Central South University. The ethical batch number was XYGW-2019-2016, and it was pre-registered in the Chinese Clinical Trial Registry with the registration number ChiCTRTRC-14005117. Before the survey began, all students in the study signed an informed consent form.

\subsection{Study Design and Participants}

This study is cross-sectional. From May to September 2019, the researchers recruited 1301 college students from two comprehensive universities in Changsha, Hunan Province, China. Inclusion criteria were as follows: (1) being undergraduates enrolled between September 2017 and September 2018; (2) having good reading comprehension ability; (3) being willing to accept the investigation and complete the questionnaire survey and physical examination. Exclusion criteria: having an acute or infectious disease at the time of investigation.

We used cluster sampling to randomly select three majors from three major categories of science and technology, liberal arts, and medicine in each university, and then selected one class from each freshman and sophomore in each major randomly, and took all students in the class as the research object. After obtaining informed consent, data were collected through electronic questionnaires. We used two methods of sample recruitment: (1) asking the tutors of each class to inform the students about the survey and (2) posting posters on campus to publicize the study. 


\subsection{Measures}

\subsubsection{Questionnaire Survey}

College students who agreed to participate in the survey scanned the QR code provided by the research group to read the electronic informed consent through their smart phones, and continued to visit and fill in the electronic questionnaire after choosing "agree." In addition to demographic information, restrained eating, anxiety symptoms, depression symptoms, perceived stress, physical activity, perception of body weight, body satisfaction, and food consumption were also examined in this way.

- Demographic characteristics: Including the student's gender, age, registered residence, ethnicity, sibling status (only child (yes vs. no)), academic major, and monthly living expenses, etc.

- Restrained eating: Restrained eating was investigated using the cognitive restraint dimension of the Chinese version of the Three-Factor Eating Questionnaire (TFEQ18V3) [21], which was revised by TFEQ-R21 [22] among Chinese college students. The Cronbach's alpha of TFEQ-18V3 was 0.87 , and the retest reliability coefficient was 0.80 . The Cronbach's alpha and retest reliability coefficient of the cognitive restrained eating dimension were 0.76 and 0.79 , respectively. The scale comprises 18 items rated with a four-point response scale. The cognitive restrained eating dimension includes five items, and the score ranges from 5 to 20 . The total score of each dimension was finally converted into a $0-100$ scale (final score $=100 \times$ [original score - theoretical lowest score] $\div$ theoretical score range). Higher scores indicate more intense $\mathrm{CR}$ (cognitive restrained eating). According to the research of Camilleri, G. M., CR scores were categorized based on the sex-specific median cut-points (excluding those with no CR): (1) no CR (score = 0); (2) low CR $(0<$ score < median); and (3) high CR (score $\geq$ median) [23].

- $\quad$ Perceived stress: Perceived stress scale-4 (PSS-4) was used to evaluate college students stress symptoms [24]. PSS-4 has been proven to have good reliability and validity in the Chinese population [25]. There are five items in the scale, and each item includes five categories of response ("never, hardly, occasionally, often, and very much," rated 0 to 4 , respectively). The score $\geq 90$ th percentile was defined as having stress symptoms [26]. A higher score means a higher degree of stress symptoms.

- Anxiety symptoms: Generalized Anxiety Disorder-2 (GAD-2) was used to investigate the anxiety status of college students [27]. GAD-2 consists of two items on a four-point response scale (from 0 , never, to 3 , almost every day). An overall score greater than 3 indicates the presence of anxiety [27]. GAD-2 has been proven to have good reliability and validity in the Chinese population [28,29].

- Depressive symptoms: Patient Health Questionnaire-9 (PHQ-9) was used to assess whether students had experienced depressive symptoms in the past two weeks [30]. The PHQ-9 consists of nine items on a four-point response scale with scores ranging from " 0 " to " 3 " respectively ("None"; "Few days"; "More than half of the days"; "Almost every day"). The overall score ranges from 0 to 27, with a higher score meaning a higher degree of depressive symptoms. Scores greater than or equal to 10 indicate the presence of depressive symptoms [30]. The Cronbach $\alpha$ reliability coefficient of the items was 0.89 .

- Physical activity: Physical activity was assessed using the short-form self-administered instruments of the International Physical Activity Questionnaire (IPAQ) [31]. The questionnaire consisted of seven items and used indicators in MET min/week (Metabolic equivalence, MET) to indicate the intensity of physical activity. The IPAQ was scored according to recommended guidelines [32]. The physical activities were categorized into low, moderate, and high, based on IPAQ guidelines. Physical activity levels were divided into three grades: low activity or inactivity, moderate physical activity, and high physical activity [32]. 
- $\quad$ Satisfaction with body image: Our survey investigated Chinese college students and their satisfaction with their body image, and the results were divided into two categories: "satisfied or indifferent" and "dissatisfied."

- Perception of body weight: According to the BMI standard of Chinese adults, the results were divided into four groups: underweight, normal, overweight, and obese. The participants' perceptions of their weight were compared to their actual BMI category, and the results were divided into three groups: correct estimates, underestimates, and overestimates.

- Food consumption: The Food Frequency Questionnaire (FFQ) was used to investigate students' food intake in the past 12 months. FFQ includes 32 kinds of food items, including nine categories of food, namely cereals and tubers, vegetables, fruits, domestic animals and poultry, aquatic products, beans and their products, dairy, eggs, and nuts. The response format ranged from 1, "Never eat," to 9, "Eat three times a day." Then, the intake frequency of 32 kinds of food was recoded into times per week: never eaten $=0,<1$ time $/$ month $=0,1-3$ times $/$ month $=0.5$ times $/$ week, 1-2 times $/$ week $=1.5$ times $/$ week, 3-4 times $/$ week $=3.5$ times $/$ week, 5-6 times $/$ week = 5.5 times $/$ week; 1 times $/$ day $=7$ times $/$ week, 2 times $/$ day $=14$ times $/$ week, 3 times $/$ day or more $=21$ times $/$ week or more. After that, food items were added according to food groups to calculate the average weekly consumption frequencies of each food group and to analyze the correlation between frequency of food intake and restrained eating. Moreover, we used dietary diversity scores (DDS) to evaluate students' dietary quality. When calculating for DDS, points can be scored if at least one food in each category is consumed once a week or more. Consuming the same type of food scored for only one point so that the highest score was 9 points. Snacks, such as sugar-sweetened beverages, were not scored. Referring to Meng et al.'s study, $>8$ was evaluated as a good level of dietary diversification, while $\leq 8$ was evaluated as low dietary diversity [33].

\subsubsection{Anthropometric Measurements}

Height and weight of each participant were measured by the Tanita Body Composition Analyzer BC-W02C (No. 2210704, 2014), and Body mass index (BMI, kg/m²) was calculated based on these data. According to the BMI standard of Chinese adults, the healthy BMI range is $18.5 \sim 23.9 \mathrm{~kg} / \mathrm{m}^{2}$. Those who were below the healthy range were underweight, those whose BMIs ranged from $24.0-27.9 \mathrm{~kg} / \mathrm{m}^{2}$ were overweight, and those who were above $28.0 \mathrm{~kg} / \mathrm{m}^{2}$ belonged to the obese group.

\subsection{Statistical Analyses}

We used SPSS 24.0 software (IBM Corp., Armonk, NY, USA) for statistical descriptions, chi-squared tests, Spearman rank correlation tests, and logistic regression analyses. Chisquared tests were used to analyze students' demographic characteristics and determine the relationship between restrained eating, body dissatisfaction, and perception of body weight. Spearman rank correlation tests were used to evaluate the correlation between restrained eating and weekly food consumption. Binary logistic regression was performed to explore the relationship between CR and dietary diversity, and 95\% confidence intervals (CI) were calculated, while an odds ratio (OR) was estimated. The significance level was set at $p<0.05$.

\section{Results}

\subsection{General Characteristics of Participants}

A total of 1307 college students participated in the survey, six unreliable information materials were eliminated, and 1301 valid data were obtained, with an effective response rate of $99.5 \%$. Table 1 shows the basic information of college students. Among them, $508(47.9 \%)$ were male and 793 (52.1\%) were female, aged 17-25 (mean = 19.8, SD = 0.9). Of the students, $46.7 \%$ were registered in cities; $45.7 \%$ of the students were only-children. 
There was a significant difference in BMI between males and females $(p<0.001)$. The mean BMI was $21.4 \mathrm{~kg} / \mathrm{m}^{2}(\mathrm{SD}=3.9)$, which was higher among males $\left(22.5 \pm 4.0 \mathrm{~kg} / \mathrm{m}^{2}\right)$ than females $20.8 \pm 3.6\left(20.8 \pm 3.6 \mathrm{~kg} / \mathrm{m}^{2}, p<0.001\right)$. Twenty-eight percent of college students overestimated their body weight, among which female students did so significantly more than male students $(80.2 \%$ vs. $19.8 \%, p<0.001)$, while $10.3 \%$ of them underestimated their body weight, among which male students did so significantly more than female students (73.0\% vs. $23.0 \%, p<0.001)$. Of the college students, $61.6 \%$ were not satisfied with their body image, among which females were significantly greater than males ( $64.8 \%$ vs. $35.2 \%$, $p<0.001$ ) (Table 1).

Table 1. General characteristics of the participants.

\begin{tabular}{|c|c|c|c|c|c|}
\hline Variables & $\mathbf{N}$ & Male (n\%) & Female (n \%) & $x^{2}$ & $p$ \\
\hline Total & 1301 & $508(39.0 \%)$ & $793(61.0 \%)$ & & \\
\hline Age & & & & 29.858 & 0.000 \\
\hline$\leq 18$ years & $195(15.2 \%)$ & $53(27.2 \%)$ & $142(72.8 \%)$ & & \\
\hline 19 years & $598(46.6 \%)$ & $213(35.6 \%)$ & $385(64.4 \%)$ & & \\
\hline 20 years & $373(29.0 \%)$ & $173(46.4 \%)$ & $200(53.6 \%)$ & & \\
\hline$\geq 21$ years & $118(9.2 \%)$ & $60(50.8 \%)$ & $58(49.2 \%)$ & & \\
\hline Registered residence & & & & 0.209 & 0.647 \\
\hline Urban & $694(53.3 \%)$ & $275(39.6 \%)$ & $419(60.4 \%)$ & & \\
\hline Rural & $607(46.7 \%)$ & $233(38.4 \%)$ & $374(61.6 \%)$ & & \\
\hline Only child & & & & 12.241 & 0.000 \\
\hline Yes & $595(45.7 \%)$ & $263(44.2 \%)$ & $332(55.8 \%)$ & & \\
\hline No & $706(54.3 \%)$ & $245(34.7 \%)$ & $461(65.3 \%)$ & & \\
\hline Major & & & & 68.661 & 0.000 \\
\hline Liberal arts & $179(13.8 \%)$ & $27(15.1 \%)$ & $152(84.9 \%)$ & & \\
\hline Science and technology & $840(64.6 \%)$ & $390(46.4 \%)$ & $450(53.6 \%)$ & & \\
\hline Medicine & $160(12.3 \%)$ & $48(30.0 \%)$ & $112(70.0 \%)$ & & \\
\hline Others & $122(9.4 \%)$ & $43(35.2 \%)$ & $79(64.8 \%)$ & & \\
\hline Monthly expenditure & & & & 13.323 & 0.004 \\
\hline$\leq 500 \mathrm{RMB}$ & $20(1.6 \%)$ & $15(75.0 \%)$ & $5(25.0 \%)$ & & \\
\hline 500-1000 RMB & $265(20.7 \%)$ & $109(41.1 \%)$ & $156(58.9 \%)$ & & \\
\hline 1000-2000 RMB & $897(69.9 \%)$ & $343(38.2 \%)$ & $554(61.8 \%)$ & & \\
\hline$>2000 \mathrm{RMB}$ & $101(7.9 \%)$ & $33(32.7 \%)$ & $68(67.3 \%)$ & & \\
\hline BMI & & & & 64.888 & 0.000 \\
\hline Underweight & $158(16.1 \%)$ & $41(25.9 \%)$ & $117(74.1 \%)$ & & \\
\hline Normal & $673(68.7 \%)$ & $238(35.4 \%)$ & $435(64.6 \%)$ & & \\
\hline Overweight & $114(11.6 \%)$ & $81(71.1 \%)$ & $33(28.9 \%)$ & & \\
\hline Obesity & $34(3.5 \%)$ & $15(44.1 \%)$ & $19(55.9 \%)$ & & \\
\hline Physical activity & & & & 13.266 & 0.001 \\
\hline Low & $276(21.2 \%)$ & $104(37.7 \%)$ & $172(62.3 \%)$ & & \\
\hline Median & $793(61.0 \%)$ & $289(36.4 \%)$ & $504(63.6 \%)$ & & \\
\hline High & $232(17.8 \%)$ & $115(49.6 \%)$ & $117(50.4 \%)$ & & \\
\hline Perceived stress & & & & 1.232 & 0.267 \\
\hline Yes & $73(5.6 \%)$ & $33(45.2 \%)$ & $40(54.8 \%)$ & & \\
\hline No & $1228(94.4 \%)$ & $475(38.7 \%)$ & $753(61.3 \%)$ & & \\
\hline Anxiety symptoms & & & & 0.286 & 0.593 \\
\hline Yes & $159(12.2 \%)$ & $59(37.1 \%)$ & $100(62.9 \%)$ & & \\
\hline No & $1142(87.8 \%)$ & $449(39.3 \%)$ & $693(60.7 \%)$ & & \\
\hline Depressive symptoms & & & & 3.336 & 0.068 \\
\hline Yes & $242(18.6 \%)$ & $107(44.2 \%)$ & $135(55.8 \%)$ & & \\
\hline No & 1059 (81.4\%) & $401(30.8 \%)$ & $658(50.6 \%)$ & & \\
\hline $\begin{array}{c}\text { Perception of body } \\
\text { weight }\end{array}$ & & & & 92.096 & 0.000 \\
\hline Underestimate & $100(10.3 \%)$ & $73(73.0 \%)$ & $27(27.0 \%)$ & & \\
\hline Correct & $601(61.7 \%)$ & $244(40.6 \%)$ & $357(59.4 \%)$ & & \\
\hline Overestimate & $273(28.0 \%)$ & $54(19.8 \%)$ & $219(80.2 \%)$ & & \\
\hline
\end{tabular}


Table 1. Cont.

\begin{tabular}{cccccc}
\hline Variables & $\mathbf{N}$ & Male (n\%) & Female (n\%) & $\chi^{2}$ & $p$ \\
\hline Satisfaction with body & & & & 13.259 & 0.000 \\
image & & & & \\
Satisfied & $499(38.4 \%)$ & $226(45.3 \%)$ & $273(54.7 \%)$ & & \\
Not satisfied & $802(61.6 \%)$ & $282(35.2 \%)$ & $520(64.8 \%)$ & & \\
\hline
\end{tabular}

Chi-square test was performed to compare the groups. BMI: body mass index; RMB: Renminbi, Chinese official coupons, $1 \mathrm{RMB} \approx 0.16 \mathrm{USD}$.

\subsection{Variables of the Three-Factor Eating Questionnaire by Sex}

We used the Three-Factor Eating Questionnaire to investigate the eating behavior of Chinese college students. The results showed that the mean score of cognitive restricted eating was $11.32 \pm 3.20$, and the score of female students was higher than that of male students $(11.78 \pm 3.13$ vs. $10.58 \pm 3.15, p<0.001)$. The same is true for the score distribution of emotional eating and uncontrolled eating, with girls scoring higher than boys on average (Table 2).

Table 2. Variables of The Three-Factor Eating Questionnaire by sex ( $x \pm \mathrm{SD})$.

\begin{tabular}{cccccc}
\hline Variables & Total & Male & Female & $\boldsymbol{t}$ & $\boldsymbol{p}$ \\
\hline Cognitive restraint & $11.32 \pm 3.20$ & $10.58 \pm 3.15$ & $11.78 \pm 3.13$ & -6.737 & 0.000 \\
Emotional eating & $12.64 \pm 4.51$ & $11.17 \pm 4.35$ & $13.58 \pm 4.36$ & -9.746 & 0.000 \\
Uncontrolled eating & $15.75 \pm 4.39$ & $14.57 \pm 4.60$ & $16.51 \pm 4.08$ & -7.737 & 0.000 \\
\hline
\end{tabular}

$t$ test was performed to compare the groups. SD: Standard deviation.

3.3. Association between Cognitive Restraint, Emotion, Perception of Body Weight, and Satisfaction with Body Image

In this study, 687 college students had high restrained eating levels, accounting for $52.8 \%$ of the total. Students with a higher BMI tended to have higher levels of restrained eating. Students who overestimated their body weight were more likely to have a high level of restrained eating $(60.8 \%$ vs. $39.2 \%, p<0.001)$, and those who were not satisfied with their body image were more likely to have a high level of restrained eating $(61.0 \%$ vs. $39.0 \%, p<0.001)$. No association was observed between perceived stress, anxiety symptoms, depressive symptoms, and restrained eating (Table 3).

Table 3. Association between CR, emotion, perception of body weight and satisfaction with body image.

\begin{tabular}{|c|c|c|c|c|c|}
\hline Variables & $\mathbf{N}$ & $\begin{array}{c}\text { No CR/Low } \\
\text { CR }(n \%)\end{array}$ & $\begin{array}{l}\text { High CR } \\
\text { (n\%) }\end{array}$ & $x^{2}$ & $p$ \\
\hline Total & 1301 & $614(47.2 \%)$ & $687(52.8 \%)$ & & \\
\hline Perceived stress & & & & 0.378 & 0.539 \\
\hline Yes & $73(5.6 \%)$ & $37(50.7 \%)$ & $36(49.3 \%)$ & & \\
\hline No & $1228(94.4 \%)$ & $577(47.0 \%)$ & $651(53.0 \%)$ & & \\
\hline Anxiety symptoms & & & & 0.451 & 0.502 \\
\hline Yes & $159(12.2 \%)$ & $79(49.7 \%)$ & $80(50.3 \%)$ & & \\
\hline No & $1142(87.8 \%)$ & $535(46.8 \%)$ & $607(53.2 \%)$ & & \\
\hline Depressive symptoms & & & & 0.293 & 0.589 \\
\hline Yes & $242(18.6 \%)$ & $118(48.8 \%)$ & $124(51.2 \%)$ & & \\
\hline No & $1059(81.4 \%)$ & $496(46.8 \%)$ & $563(53.2 \%)$ & & \\
\hline $\begin{array}{l}\text { Perception of body } \\
\text { weight }\end{array}$ & & & & 18.620 & 0.000 \\
\hline Underestimate & $100(10.3 \%)$ & $63(63.0 \%)$ & $37(37.0 \%)$ & & \\
\hline Correct & $601(61.7 \%)$ & $302(50.2 \%)$ & $299(49.8 \%)$ & & \\
\hline Overestimate & $273(28.0 \%)$ & $107(39.2 \%)$ & $166(60.8 \%)$ & & \\
\hline $\begin{array}{c}\text { Satisfaction with body } \\
\text { image }\end{array}$ & & & & 55.964 & 0.000 \\
\hline
\end{tabular}


Table 3. Cont.

\begin{tabular}{cccccc}
\hline Variables & $\mathbf{N}$ & $\begin{array}{c}\text { No CR/Low } \\
\text { CR (n\%) }\end{array}$ & $\begin{array}{c}\text { High CR } \\
(\mathbf{n} \%)\end{array}$ & $\chi^{2}$ & $p$ \\
\hline Satisfied & $499(38.4 \%)$ & $301(60.3 \%)$ & $198(39.7 \%)$ & & \\
Not satisfied & $802(61.6 \%)$ & $313(39.0 \%)$ & $489(61.0 \%)$ & & \\
BMI & & & & 53.883 & 0.000 \\
Underweight & $158(16.1 \%)$ & $116(73.4 \%)$ & $42(26.6 \%)$ & & \\
Normal & $673(68.7 \%)$ & $306(45.5 \%)$ & $367(54.5 \%)$ & & \\
Overweight & $114(11.6 \%)$ & $41(36.0 \%)$ & $73(64.0 \%)$ & & \\
Obesity & $34(3.5 \%)$ & $10(29.4 \%)$ & $24(70.6 \%)$ & & \\
\hline
\end{tabular}

CR: cognitive restrained eating; BMI: body mass index; Chi-squared test was performed to compare the groups.

\subsection{Correlation between Cognitive Restraint Eating and Weekly Consumption Frequency of Food and Snacks}

Spearman rank correlation tests were used to analyze the correlation between restraint eating and weekly consumption frequency of food and snacks. Results showed that a high level of restrained eating was related to higher frequencies of eating eggs $(p<0.01)$ and fruits $(p<0.001)$ and lower frequencies of eating domestic animals and poultry, sugarsweetened beverages, and fast food $(p<0.001)$ (Table 4$)$.

Table 4. Correlation between cognitive restraint eating and weekly consumption frequency of food and snacks.

\begin{tabular}{cccc}
\hline Food Group & Median (P25, P75) & Correlation Coefficient & $p$ \\
\hline Cereals and tubers & $22.0(16.0,29.0)$ & -0.041 & 0.140 \\
Vegetables & $12.0(6.0,19.5)$ & 0.030 & 0.286 \\
Fruits & $9.5(4.5,17.0)$ & 0.100 & 0.000 \\
Domestic animals and Poultry & $10.5(6.0,15.5)$ & -0.129 & 0.000 \\
Aquatic products & $1.0(0.0,2.0)$ & -0.020 & 0.462 \\
Beans and their products & $5.0(2.0,7.0)$ & -0.001 & 0.966 \\
Dairy & $3.5(1.5,5.5)$ & 0.034 & 0.223 \\
Eggs & $3.5(1.5,5.5)$ & 0.075 & 0.006 \\
Nuts & $0.5(0.0,1.5)$ & 0.029 & 0.297 \\
Fast food & $1.5(0.5,3.0)$ & -0.146 & 0.000 \\
Sugar-sweetened beverages & $1.5(0.5,3.5)$ & -0.249 & 0.000 \\
\hline
\end{tabular}

Spearman rank correlation test was performed to analyze the between restraint eating and food consumption frequencies.

\subsection{Dietary Diversity Score by Cognitive Restraint}

Binary logistic regression analysis was conducted with a "dietary diversity score $\leq 8$ " (reference $=">8$ ") as the dependent variable to explore the relationship between restricted eating and dietary diversity. College students with high levels of restrained eating were more likely to have low levels of dietary diversity compared to those with no or low levels of restrained eating ( $\mathrm{OR}=1.384,95 \% \mathrm{CI}$ : 1.002 1.912) (Table 5, model 2). This association remained after adjusting for emotional and uncontrolled eating.

Table 5. Logistic regression analysis of the related factors of dietary diversity scores (DDS) among participants.

\begin{tabular}{cccc}
\hline Variables & \multicolumn{3}{c}{$\begin{array}{c}\text { Dietary Diversity Score } \leq 8 \\
\text { OR (95\%CI) }\end{array}$} \\
\hline & Crude OR & Model 1 & Model 2 \\
\hline $\begin{array}{c}\text { Cognitive restraint } \\
(\text { reference }=\text { “No CR/Low CR”) } \\
\text { High CR }\end{array}$ & $1.395(1.038,1.875) *$ & & \\
\hline
\end{tabular}


Table 5. Cont.

\begin{tabular}{cccc}
\hline Variables & \multicolumn{3}{c}{$\begin{array}{c}\text { Dietary Diversity Score } \leq \mathbf{8} \\
\text { OR (95\% CI) }\end{array}$} \\
\hline & Crude OR & Model 1 & Model 2 \\
\hline $\begin{array}{c}\text { Emotional eating } \\
\text { (reference }=\text { "No EE/Low EE”) } \\
\text { High EE }\end{array}$ & $1.313(0.978,1.763)$ & \\
$\begin{array}{c}\text { Uncontrolled eating } \\
\text { (reference }=\text { "No UE/Low UE”) } \\
\text { High UE }\end{array}$ & $1.232(0.915,1.658)$ & $1.157(0.828,1.617)$ \\
\hline
\end{tabular}

Model 1: adjusted for sex, age, registered residence, monthly expenditure, major, physical activity, perceived stress, anxiety symptoms, depressive symptoms, and satisfaction to body image; Model 2: additionally adjusted for emotional eating and uncontrolled eating; ${ }^{*} p<0.05$; EE: emotional eating; UE: uncontrolled eating. OR, odds ratio. $95 \% \mathrm{CI}, 95 \%$ confidence interval.

\section{Discussion}

The main purpose of this study was to investigate the relationship between restrained eating, body image, and dietary intake among Chinese college students through the ThreeFactor Eating Questionnaire. The results showed that there were 687 college students with high restrained eating levels, accounting for $52.8 \%$ of the total. The mean restrained eating score was $11.32 \pm 3.20$, which was consistent with the results from other countries and regions [34,35]. Moreover, other studies using median or quartile to describe restrained eating have shown a high prevalence of high-level restrained eating in the population [36-38]. However, it is necessary to unify the two methods before comparing the results. Furthermore, our study found that female students scored significantly higher than male students $(11.78 \pm 3.13$ vs. $10.58 \pm 3.15, p<0.001)$. Similar results have been found in studies of adults in France, Britain, and Finland $[35,37,39]$. This may be related to the more demanding social expectations of women's body image [40]. It also could have something to do with the fact that women are more likely to be interested in energy-dense foods such as sweets, and, thus, more likely to engage in food-restricting behavior [41]. Our study also found that the scores of both emotional eating and uncontrolled eating among Chinese college students were higher for women than men, while the results of previous surveys were inconsistent $[42,43]$.

In this study, college students with higher BMIs were more likely to be highly restrained eaters, and such a positive association was also found in other studies [44,45]. There are different explanations for these results. Being overweight is usually considered to be the result of restrained eating: the restraint theory suggests that dieters who try to cognitively control their food intake are prone to lose control of their diet and even turn to overeating when their cognitive process is disturbed (disinhibition phenomenon) [46]. These factors include depressive emotions and the intake of delicious food and alcohol $[47,48]$. Apart from disinhibition, it could also be explained in part by the fact that heavier people are more likely to diet [49]. Studies have shown that a higher BMI predicts dietary restraint, while dietary restraint does not predict future weight change. Restrained eating is, therefore, a marker of past weight gain, rather than a cause of future weight gain [50]. In a follow-up study of 3297 Finnish men and women aged 25 to 74 years, baseline restrained eating was not associated with a change in BMI at seven years. On the contrary, a higher baseline BMI predicted a larger increase in dietary restriction at seven years [51]. The possible explanation for restrained eating not predicting weight loss is that dieters were not dieting enough to reach the purpose of weight loss [50,52]. For example, they were not strict enough in reducing their food intake: although they ate less than they wanted, they actually ate no less than their physiological needs and not enough to have an effect on their weight [53].

When comparing self-estimated BMI with measured BMI, we found that college students who overestimated their body weight accounted for $28.0 \%$ of the total number of students, and those who were not satisfied with their body image accounted for $61.6 \%$ of 
the total number of students (Table 1). Moreover, students who overestimated their body weight $(60.8 \%$ vs. $39.2 \%, p<0.001)$ or were dissatisfied with their body image were both more likely to have high dietary-restraint tendencies (61.0\% vs. 39.0\%, $p<0.001)$ (Table 3). Meanwhile, students not satisfied with their body size were more likely to overestimate their body weight (see Appendix A, Table A1).

A study of Lebanese adults also found a link between body dissatisfaction and restrained eating and observed that pressure from social media to lose weight was also a contributing factor in restrained eating [18]. There may be a psychological explanation for this phenomenon. According to sociocultural theory, sociocultural factors play a central role in the development of human cognitive ability. Internalization is a core concept of sociocultural theory. This means that individuals demand their own behavior according to certain values and social standards formed in social culture [54]. The current social culture has shaped an ideal standard of thinness being beautiful, and this standard has become the social standard of individual image. Individuals internalize the ideal of slimness, and when there is a gap between their actual image and the ideal image, they will produce negative body images, which will lead to restrained eating behaviors [20,55].

According to social comparison theory, when there is no objective comparison standard, individuals will compare those people who are like them. Social comparison of body image has a significant impact on one's self-evaluation [56]. Family, peers, and media factors are the most likely to lead to negative body image $[57,58]$. The pressure to be thin from family, peers, and the media together with the internalization of being thin as ideal creates conditions for a negative body image [59], which have been exacerbated by the development of new media such as We Media and social networking sites in recent years. Compared with traditional media, new media contain more socio-cultural pressures, which further exacerbates the cult of thinness [60].

Social and mass media used for interpersonal communication, including photos, video logs, and other personal information, are highly interactive. On social networking sites, people can make public comments on other peoples' posts [61]. Moreover, publishing self-images have made women more likely to be judged by their peers over their appearance [62]. All these make social networking sites an important place for individuals to make social comparisons (mainly body image comparisons) [63]. The results show that girls who regularly share their self-images on social media tend to overestimate their body shape and weight and have higher levels of body dissatisfaction and dietary restriction compared to girls who do not use social media [64]. Social media use is also more strongly associated with body dissatisfaction than any other Internet-related activity [65].

Our study shows that in both college students who overestimate their body weight $(80.2 \%$ vs. $19.8 \%, p<0.001)$ and those who are dissatisfied with their body image $(64.8 \%$ vs. $35.2 \%, p<0.001)$, female students do so significantly more than male students. However, male students underestimated their body weight significantly more than did female students $(73.0 \%$ vs. $23.0 \%, p<0.001)$ (Table 1$)$, with the social culture related to the different expectations for both men and women.

These results have to do with the different cultural expectations of men and women. Women must be thin to be physically attractive. This social culture of thinness encourages women to try to become thinner, such as by restricting their diet. While the social culture generally requires men to be stronger, men who want to lose weight tend to use exercise as a means of weight control [40]. This is supported by research from other regions: a survey of the body size of college students in 22 different countries and regions found that more women than men identified themselves as overweight in any decile. Women tended to overestimate their weight, while men did not. Women were more likely to lose weight when they self-evaluated as overweight, while even men in the highest BMI decile were less aware of their overweight status and less likely to try to lose weight. The study also found that both men and women in Asian countries showed higher levels of dieting, which is related to the social culture of Asian countries, where people's ideal weight is generally lower than in the United States and Europe [66]. 
We also investigated the relationship between restrained eating and dietary intake in college students. For sugar-sweetened beverages and fast food, the higher the restrained eating score, the lower the frequency of consumption (Table 4). The same results were found in a French study of 887 people [67], where high-level restrained eaters had lower intakes of sweets and sugar-sweetened beverages, and restrained eating was associated with reduced total energy intake $[67,68]$. This may be related to the fact that restrained eaters pay more attention to the calorie content of their food, which increases their motivation to suppress appetite and their ability to reduce unhealthy food intake [69].

Second, the subjects of our study were freshmen and sophomores, and the correlation between high restrained eating and decreased food cravings was more obvious in the younger group $[34,70]$. The study showed a much stronger negative association between the level of restrained eating and cravings for high-fat, sweet, and fast-food foods in the $\leq 25$ age group than in the $>25$ age group, the sweets craving was strongly influenced by gender in the $\leq 25$ age group, and the correlation was more pronounced in women [34,70].

In addition to the reduction in the intake of unhealthy foods, restrained eating was also associated with changes in the intake of healthy foods. We observed a negative correlation between the frequency of domestic animals and poultry intake and restrained eating scores, but the opposite was observed for fruits and eggs (Table 4). Another study of 596 female college students also found that the likelihood of participants following a lacto-ovo or vegan diet increased significantly as the level of restrained eating increased [38]. This may be related to the low energy and fat content of these foods, and restrained eaters are more inclined to choose these foods to control calorie and fat intake [5]. However, when comparing the levels of restrained eating between vegetarians and omnivores, the vegetarians had lower levels of restrained eating. A possible explanation is that in omnivores, restriction counteracts the effects of overeating and, thus, helps to control weight, whereas vegetarians, who have little inclination to overeat, have lower levels of restriction [71,72].

We also used the DDS for the first time to evaluate the dietary quality of restrained eating college students. The results showed that college students with high restrained eating were more likely to have low levels of dietary diversity than those with no or low restrictive eating $(\mathrm{OR}=1.384,95 \% \mathrm{CI}$ : 1.002 1.912) (Table 5, model 2). Previous studies have shown that individuals with high restrained eating are more likely to choose low-energy and healthier foods, which tends to make them reduce energy-rich foods such as cereals and tubers, and domestic animals and poultry, and switch to vegetables and fruits, leading to a decrease in food diversity $[70,73]$. Meanwhile, excessive restriction of energy intake may also bring further negative health effects, such as the lack of carbohydrates and fat in vegetarian diets, which may lead to an increased incidence of menstrual disorders in women [38]. This association between high levels of dietary restraint and irregular menstruation may have further implications for women's health. In addition to the obvious effects on fertility, bone health may also be affected; menstrual dysfunction can affect circulating steroids and is known to cause bone loss [74]. Moreover, a review of the health effects of low-carbohydrate diets showed that while short-term carbohydrate restriction of more than a week can lead to significant weight loss, this type of diet may pose potential health hazards over a longer period of months to years. Complications including arrhythmia, cardiac systolic dysfunction, sudden death, osteoporosis, kidney damage, increased risk of cancer, physical activity disorders, and lipid abnormalities may be related to long-term dietary carbohydrate restrictions [75].

Relevant studies have been carried out to intervene in restrained eating or dieting and the accompanying negative body image. Cognitive intervention based on school or community showed urging participants to correctly deal with sociocultural pressure and reducing their ideal internalization of thinness to be an effective intervention. It helps to promote participants to establish the correct perception of body weight and positive body image, form good eating habits and reduce the risk of eating disorders and related diseases [76,77]. However, the follow-up results show that the intervention effect is not clear. Long-term and more intensive interventions are still needed to lastingly change 
the body image and dieting behavior [76,77]. Another 8-week intervention in college-age women with high weight and body size concerns showed that Internet-based cognitive behavioral intervention could significantly reduce weight and body size concerns for up to two years and reduce the incidence of eating disorders [78]. Other effective interventions include nutrition education and theory-based behavior change interventions [79]. It is worth noting that in a physical activity intervention designed to prevent dieting and excessive concerns about weight, physical activity interventions may increase concerns about women's slimness; therefore, health promotion research should include the assessment of potential negative side effects [80].

This study investigated the incidence of high-level restrained eating, body dissatisfaction, and misperception of body weight among freshmen and sophomores in China. The results help understand young people's attitudes towards body image and provide a reference for guiding them to recognize body shape and establishing healthy eating behaviors correctly. We also used DDS for the first time to evaluate college students' dietary quality and explored the relationship between restrained eating and dietary intake. The results provide a basis for the dietary guidance and nutrition education for college students with restrained eating and the formulation of dietary health-related policies in the future.

However, the study has its limitations. First of all, due to the large sample size and content of our questionnaire and the limited survey time (between two categories), this study used FFQ as a diet survey tool. Considering the low accuracy of food intake self-estimates, we did not set items to investigate the amount of food consumed. Therefore, participants' diet quality can only be roughly assessed by the frequency of food intake and DDS. Further research is needed to explore the impact of restrictive eating on the quality of students' diets. Secondly, in the process of sample collection, due to the different degree of completion and participation rate of students, participants majoring in science and technology account for a high proportion of the sample population. Therefore, this sample cannot reflect the restrained eating behaviors, body image, and dietary intake of all Chinese college students. Finally, only cross-sectional data were collected in this study, so it is not possible to determine the sequence and possible interaction between restrained eating, body image, and dietary intake in students. In future studies, a large, prospective, population-based study should be conducted to follow up restrained eating behaviors in the sample and evaluate their interaction with body image and dietary intake.

\section{Conclusions}

In this study, we found that the incidence of high restrained eating among Chinese college students was at a high level. College students who overestimated their body weight or who were dissatisfied with their body image had a higher tendency to restrain their eating. Moreover, college students with high restrained eating may have controlled their dietary energy intake by reducing their intake frequency of energy-dense foods such as sugar-sweetened beverages and fast food and increasing their intake of low-energy foods such as eggs and fruits. Long-term adoption of such a calorie-restricted diet has been shown to have a variety of potential short- and long-term health implications; thus, the high prevalence of restrained eating among Chinese college students needs attention. Further studies are needed to investigate the characteristics of Chinese college students' restrained eating to help tailor interventions targeting establishing correct perception of body weight and positive body image, forming healthy eating behaviors.

Author Contributions: Conceptualization and methodology, Q.L. and H.L.; software and validation, H.L.; formal analysis, H.L. and C.Y.; investigation, H.L., Q.Y., J.L., Y.O., M.S., C.Y., Y.X. and C.X.; resources, Q.L. and H.L.; data curation, H.L. and C.Y.; writing-original draft preparation, C.Y., writing-review and editing, C.Y.; supervision, Q.L. and H.L.; project administration, Q.L. and H.L.; funding acquisition, Q.L. and H.L. All authors interpreted the results and made a substantial contribution to the improvement of the manuscript. All authors read the final manuscript and approved this submission. All authors have read and agreed to the published version of the manuscript. 
Funding: This research was supported by National Natural Science Foundation of China 81903404.

Institutional Review Board Statement: The study was conducted according to the guidelines of the Declaration of Helsinki, and approved by the Ethics Committee of the Xiangya School of Public Health, Central South University (XYGW-2019-2016).

Informed Consent Statement: Informed consent was obtained from all subjects involved in the study.

Data Availability Statement: The data that support the findings of this study are not publicly available due to the data containing information that could compromise participant privacy but are available from the corresponding author on reasonable request.

Acknowledgments: We would like to thank all the teachers and students in those two universities. We are also grateful to the teachers and students from the Xiangya School of Public Health, Central South University, in Changsha, China, for their assistance in this investigation.

Conflicts of Interest: The authors declare no conflict of interest. The funders had no role in the design of the study; in the collection, analyses, or interpretation of data; in the writing of the manuscript, or in the decision to publish the results.

\section{Appendix A}

Table A1. Perception of body weight and BMI by satisfaction with body image.

\begin{tabular}{|c|c|c|c|c|c|}
\hline Variables & $\mathbf{N}$ & $\begin{array}{c}\text { Satisfied with } \\
\text { Body Image (n\%) }\end{array}$ & $\begin{array}{l}\text { Not Satisfied with } \\
\text { Body Image (n\%) }\end{array}$ & $x^{2}$ & $p$ \\
\hline Total & 1301 & $370(38.0 \%)$ & $604(62.0 \%)$ & & \\
\hline Perception of body weight & & & & 34.999 & 0.000 \\
\hline Underestimate & $100(10.3 \%)$ & $48(48.0 \%)$ & $52(52.0 \%)$ & & \\
\hline Correct & $601(61.7 \%)$ & $258(42.9 \%)$ & $343(57.1 \%)$ & & \\
\hline Overestimate & $273(28.0 \%)$ & $64(23.4 \%)$ & $209(76.6 \%)$ & & \\
\hline BMI & & & & 43.784 & 0.000 \\
\hline Underweight & $158(16.1 \%)$ & $89(56.3 \%)$ & $69(43.7 \%)$ & & \\
\hline Normal & $673(68.7 \%)$ & $255(37.9 \%)$ & $418(62.1 \%)$ & & \\
\hline Overweight & $114(11.6 \%)$ & $22(19.3 \%)$ & $92(80.7 \%)$ & & \\
\hline Obesity & $34(3.5 \%)$ & $7(20.6 \%)$ & $27(79.4 \%)$ & & \\
\hline
\end{tabular}

Chi-square test was performed to compare the groups; BMI: body mass index.

\section{References}

1. Herman, C.P.; Mack, D. Restrained and unrestrained eating. J. Pers. 1975, 43, 647-660. [CrossRef]

2. Kong, F.; Zhang, Y.; Chen, H.; Shi, M.; Jackson, T.; Gao, X. The cognitive bias in food cues for restricted eaters: Evidences from behavioral and neuropsychologic studies. Adv. Psychol. Sci. 2011, 19, 1355-1362.

3. Neumark-Sztainer, D.; Wall, M.; Guo, J.; Story, M.; Haines, J.; Eisenberg, M. Obesity, disordered eating, and eating disorders in a longitudinal study of adolescents: How do dieters fare 5 years later? J. Am. Diet. Assoc. 2006, 106, 559-568. [CrossRef] [PubMed]

4. Laessle, R.; Hilterscheid, E. Stress-Induced Release of Eating-Related Hormones in Young Women Classified as Restrained and Unrestrained Eaters. Neuropsychobiology 2019, 78, 27-30. [CrossRef] [PubMed]

5. Zambrowicz, R.; Schebendach, J.; Sysko, R.; Mayer, L.E.S.; Walsh, B.T.; Steinglass, J.E. Relationship between three factor eating questionnaire-restraint subscale and food intake. Int. J. Eat. Disord. 2019, 52, 255-260. [CrossRef] [PubMed]

6. Wood, K.L.; Barrack, M.T.; Gray, V.B.; Cotter, J.A.; Van Loan, M.D.; Rauh, M.J.; McGowan, R.; Nichols, J.F. Cognitive dietary restraint score is associated with lower energy, carbohydrate, fat, and grain intake among female adolescent endurance runners. Eat. Behav. 2020, 40, 101460. [CrossRef]

7. Elran-Barak, R.; Sztainer, M.; Goldschmidt, A.B.; Crow, S.J.; Peterson, C.B.; Hill, L.L.; Crosby, R.D.; Powers, P.; Mitchell, J.E.; Le Grange, D. Dietary Restriction Behaviors and Binge Eating in Anorexia Nervosa, Bulimia Nervosa and Binge Eating Disorder: Trans-diagnostic Examination of the Restraint Model. Eat. Behav. 2015, 18, 192-196. [CrossRef]

8. Rawana, J.S.; McPhie, M.L.; Hassibi, B. Eating- and weight-related factors associated with depressive symptoms in emerging adulthood. Eat. Behav. 2016, 22, 101-108. [CrossRef]

9. Joseph, P.V.; Davidson, H.R.; Boulineaux, C.M.; Fourie, N.H.; Franks, A.T.; Abey, S.K.; Henderson, W.A. Eating Behavior, Stress, and Adiposity: Discordance Between Perception and Physiology. Biol. Res. Nurs. 2018, 20, 531-540. [CrossRef]

10. Arnett, J.J. Emerging adulthood. A theory of development from the late teens through the twenties. Am. Psychol. 2000, 55, 469-480. [CrossRef] [PubMed] 
11. Hootman, K.C.; Guertin, K.A.; Cassano, P.A. Stress and psychological constructs related to eating behavior are associated with anthropometry and body composition in young adults. Appetite 2018, 125, 287-294. [CrossRef]

12. Ohara, K.; Mase, T.; Kouda, K.; Miyawaki, C.; Momoi, K.; Fujitani, T.; Fujita, Y.; Nakamura, H. Association of anthropometric status, perceived stress, and personality traits with eating behavior in university students. Eat. Weight Disord. EWD 2019, 24, 521-531. [CrossRef]

13. Jáuregui-Lobera, I.; García-Cruz, P.; Carbonero-Carreño, R.; Magallares, A.; Ruiz-Prieto, I. Psychometric properties of Spanish version of the Three-Factor Eating Questionnaire-R18 (Tfeq-Sp) and its relationship with some eating- and body image-related variables. Nutrients 2014, 6, 5619-5635. [CrossRef]

14. Tang, C.; Cooper, M.; Wang, S.; Song, J.; He, J. The relationship between body weight and dietary restraint is explained by body dissatisfaction and body image inflexibility among young adults in China. Eat. Weight Disord. EWD 2020, (Suppl. 2), 3. [CrossRef] [PubMed]

15. Wang, K.; Liang, R.; Ma, Z.L.; Chen, J.; Cheung, E.F.C.; Roalf, D.R.; Gur, R.C.; Chan, R.C.K. Body image attitude among Chinese college students. Psych J. 2018, 7, 31-40. [CrossRef] [PubMed]

16. Ohara, K.; Kato, Y.; Mase, T.; Kouda, K.; Miyawaki, C.; Fujita, Y.; Okita, Y.; Nakamura, H. Eating behavior and perception of body shape in Japanese university students. Eat. Weight Disord. EWD 2014, 19, 461-468. [CrossRef] [PubMed]

17. Doumit, R.; Zeeni, N.; Ruiz, M.J.S.; Khazen, G. Anxiety as a Moderator of the Relationship Between Body Image and Restrained Eating. Perspect. Psychiatr. Care 2016, 52, 254-264. [CrossRef]

18. Saade, S.; Hallit, S.; Haddad, C.; Hallit, R.; Akel, M.; Honein, K.; Akiki, M.; Kheir, N.; Obeid, S. Factors associated with restrained eating and validation of the Arabic version of the restrained eating scale among an adult representative sample of the Lebanese population: A cross-sectional study. J. Eat. Disord. 2019, 7, 24. [CrossRef]

19. Calogero, R.M.; Boroughs, M.; Thompson, J.K. The Impact of Western Beauty Ideals on the Lives of Women: A Sociocultural Perspective. In The Body Beautiful; Palgrave Macmillan: London, UK, 2007; pp. 259-298.

20. Winzelberg, A.J.; Eppstein, D.; Eldredge, K.L.; Wilfley, D.; Dasmahapatra, R.; Dev, P.; Taylor, C.B. Effectiveness of an Internet-based program for reducing risk factors for eating disorders. J. Consult. Clin. Psychol. 2000, 68, 346-350. [CrossRef] [PubMed]

21. Zhang, T.; Hao, Y.; Yuan, H.; Bu, P. Validity and reliability of Chinese version of Three-Factor Eating Questionnaire R21 for assessment of sample of college students. Chin. Nurs. Res. 2016, 30, 4137-4141.

22. Rosnah, I.; Hassim, I.N.; Shafizah, A.S. A Systematic Translation and Cultural Adaptation Process for Three-Factor Eating Questionnaire (TFEQ-R21). Med. J. Malays. 2013, 68, 424-434.

23. Camilleri, G.M.; Méjean, C.; Kesse-Guyot, E.; Andreeva, V.A.; Bellisle, F.; Hercberg, S.; Péneau, S. The associations between emotional eating and consumption of energy-dense snack foods are modified by sex and depressive symptomatology. J. Nutr. 2014, 144, 1264-1273. [CrossRef]

24. Cohen, S.; Kamarck, T.; Mermelstein, R. A global measure of perceived stress. J. Health Soc. Behav. 1983, 24, 385-396. [CrossRef]

25. Leung, D.Y.; Lam, T.H.; Chan, S.S. Three versions of Perceived Stress Scale: Validation in a sample of Chinese cardiac patients who smoke. BMC Public Health 2010, 10, 513. [CrossRef]

26. Hlodversdottir, H.; Petursdottir, G.; Carlsen, H.K.; Gislason, T.; Hauksdottir, A. Long-term health effects of the Eyjafjallajökull volcanic eruption: A prospective cohort study in 2010 and 2013. BMJ Open 2016, 6, e011444. [CrossRef] [PubMed]

27. Kroenke, K.; Spitzer, R.L.; Williams, J.B.; Monahan, P.O.; Löwe, B. Anxiety disorders in primary care: Prevalence, impairment, comorbidity, and detection. Ann. Intern Med. 2007, 146, 317-325. [CrossRef] [PubMed]

28. Guo, N.; Luk, T.T.; Ho, S.Y.; Lee, J.J.; Shen, C.; Oliffe, J.; Chan, S.S.; Lam, T.H.; Wang, M.P. Problematic Smartphone Use and Mental Health in Chinese Adults: A Population-Based Study. Int. J. Environ. Res. Public Health 2020, 17, 844. [CrossRef] [PubMed]

29. Luo, Z.; Li, Y.; Hou, Y.; Zhang, H.; Liu, X.; Qian, X.; Jiang, J.; Wang, Y.; Liu, X.; Dong, X.; et al. Adaptation of the two-item generalized anxiety disorder scale (GAD-2) to Chinese rural population: A validation study and meta-analysis. Gen. Hosp. Psychiatry 2019, 60, 50-56. [CrossRef] [PubMed]

30. Kroenke, K.; Spitzer, R.L.; Williams, J.B.W. The PHQ-9: Validity of a brief depression severity measure. J. Gen. Intern. Med. 2001, 16, 606-613. [CrossRef]

31. Craig, C.L.; Marshall, A.L.; Sjöström, M.; Bauman, A.E.; Booth, M.L.; Ainsworth, B.E.; Pratt, M.; Ekelund, U.; Yngve, A.; Sallis, J.F.; et al. International physical activity questionnaire: 12-country reliability and validity. Med. Sci. Sports Exerc. 2003, 35, 1381-1395. [CrossRef]

32. Fan, M.; Lyu, J.; He, P. Chinese guidelines for data processing and analysis concerning the International Physical Activity Questionnaire. J. Chin. Med. 2014, 35, 961-964.

33. Meng, L.; Wang, Y.; Li, T.; Loo-Bouwman, C.A.V.; Zhang, Y.; Man-Yau Szeto, I. Dietary Diversity and Food Variety in Chinese Children Aged 3-17 Years: Are They Negatively Associated with Dietary Micronutrient Inadequacy? Nutrients 2018, $10,1674$. [CrossRef]

34. Abdella, H.M.; El Farssi, H.O.; Broom, D.R.; Hadden, D.A.; Dalton, C.F. Eating Behaviours and Food Cravings; Influence of Age, Sex, BMI and FTO Genotype. Nutrients 2019, 11, 377. [CrossRef] [PubMed]

35. Keskitalo, K.; Tuorila, H.; Spector, T.D.; Cherkas, L.F.; Knaapila, A.; Kaprio, J.; Silventoinen, K.; Perola, M. The Three-Factor Eating Questionnaire, body mass index, and responses to sweet and salty fatty foods: A twin study of genetic and environmental associations. Am. J. Clin. Nutr. 2008, 88, 263-271. [CrossRef] [PubMed] 
36. Kemmotsu, N.; Murphy, C. Restrained eaters show altered brain response to food odor. Physiol. Behav. 2006, 87, 323-329. [CrossRef]

37. López, A.L.O.; Johnson, L. Associations between Restrained Eating and the Size and Frequency of Overall Intake, Meal, Snack and Drink Occasions in the UK Adult National Diet and Nutrition Survey. PLoS ONE 2016, 11, e0156320. [CrossRef] [PubMed]

38. McLean, J.A.; Barr, S.I. Cognitive dietary restraint is associated with eating behaviors, lifestyle practices, personality characteristics and menstrual irregularity in college women. Appetite 2003, 40, 185-192. [CrossRef]

39. Lesdéma, A.; Fromentin, G.; Daudin, J.J.; Arlotti, A.; Vinoy, S.; Tome, D.; Marsset-Baglieri, A. Characterization of the Three-Factor Eating Questionnaire scores of a young French cohort. Appetite 2012, 59, 385-390. [CrossRef] [PubMed]

40. Murray, S.B.; Touyz, S.W. Masculinity, Femininity and Male Body Image: A Recipe for Future Research. Int. J. Mens Health 2012, 11, 227-239. [CrossRef]

41. Chao, A.; Grilo, C.M.; White, M.A.; Sinha, R. Food cravings mediate the relationship between chronic stress and body mass index. J. Health Psychol. 2015, 20, 721. [CrossRef] [PubMed]

42. de Lauzon-Guillain, B.; Basdevant, A.; Romon, M.; Karlsson, J.; Borys, J.M.; Charles, M.A. Is restrained eating a risk factor for weight gain in a general population? Am. J. Clin. Nutr. 2006, 83, 132-138. [CrossRef] [PubMed]

43. Hainer, V.; Kunesova, M.; Bellisle, F.; Parizkova, J.; Braunerova, R.; Wagenknecht, M.; Lajka, J.; Hill, M.; Stunkard, A. The Eating Inventory, body adiposity and prevalence of diseases in a quota sample of Czech adults. Int. J. Obes. (Lond.) 2006, 30, 830-836. [CrossRef] [PubMed]

44. Field, A.E.; Austin, S.B.; Taylor, C.B.; Malspeis, S.; Rosner, B.; Rockett, H.R.; Gillman, M.W.; Colditz, G.A. Relation between dieting and weight change among preadolescents and adolescents. Pediatrics 2003, 112, 900-906. [CrossRef]

45. Stice, E.; Presnell, K.; Shaw, H.; Rohde, P. Psychological and behavioral risk factors for obesity onset in adolescent girls: A prospective study. J. Consult Clin. Psychol. 2005, 73, 195-202. [CrossRef] [PubMed]

46. Herman, C.P.; Polivy, J.; Leone, T. The psychology of overeating. Food Diet Obes. 2005, 115-136.

47. Lowe, M.R. The effects of dieting on eating behavior: A three-factor model. Psychol. Bull. 1993, 114, 100-121. [CrossRef]

48. Westenhoefer, J.; Broeckmann, P.; Münch, A.K.; Pudel, V. Cognitive control of eating behaviour and the disinhibition effect. Appetite 1994, 23, 27-41. [CrossRef]

49. Hill, A.J. Does dieting make you fat? Br. J. Nutr. 2004, 92 (Suppl. 1), S15-S18. [CrossRef]

50. Snoek, H.M.; van Strien, T.; Janssens, J.M.; Engels, R.C. Restrained eating and BMI: A longitudinal study among adolescents. Health Psychol. Off. J. Div. Health Psychol. Am. Psychol. Assoc. 2008, 27, 753-759. [CrossRef]

51. Konttinen, H.; Llewellyn, C.; Silventoinen, K.; Joensuu, A.; Männistö, S.; Salomaa, V.; Jousilahti, P.; Kaprio, J.; Perola, M.; Haukkala, A. Genetic predisposition to obesity, restrained eating and changes in body weight: A population-based prospective study. Int. J. Obes. (Lond.) 2018, 42, 858-865. [CrossRef]

52. Brugman, E.; Meulmeester, J.F.; Spee-van der Wekke, A.; Beuker, R.J.; Zaadstra, B.M.; Radder, J.J.; Verloove-Vanhorick, P.S. Dieting, weight and health in adolescents in The Netherlands. Int. J. Obes. Relat. Metab. Disord. 1997, 21, 54-60. [CrossRef] [PubMed]

53. Lowe, M.R.; Levine, A.S. Eating motives and the controversy over dieting: Eating less than needed versus less than wanted. Obes. Res. 2005, 13, 797-806. [CrossRef] [PubMed]

54. Low, K.G.; Charanasomboon, S.; Brown, C.; Hiltunen, G.; Long, K.; Reinhalter, K.; Jones, H. Internalization of the thin ideal, weight and body image concerns. Soc. Behav. Personal. Int. J. 2003, 31, 81-89. [CrossRef]

55. Albertson, N.K. Internalization of Western Culture's Thin-Ideal: A Literature Review on Internalization and Individuals with Eating Disorders. Ph.D. Dissertation, Biola University, La Mirada, CA, USA, 2003.

56. Holland, G.; Tiggemann, M. A systematic review of the impact of the use of social networking sites on body image and disordered eating outcomes. Body Image 2016, 17, 100-110. [CrossRef] [PubMed]

57. Thompson, J.K. Exacting Beauty: Theory, Assessment and Treatment of Body Image Disturbance. Behav. Res. Ther. 1998, 23, 94.

58. Jucker, J.L.; Thornborrow, T.; Beierholm, U.; Burt, D.M.; Barton, R.A.; Evans, E.H.; Jamieson, M.A.; Tovée, M.J.; Boothroyd, L.G. Nutritional status and the influence of TV consumption on female body size ideals in populations recently exposed to the media. Sci. Rep. 2017, 7, 8438. [CrossRef]

59. Rodgers, R.F.; Mclean, S.A.; Paxton, S.J. Longitudinal Relationships Among Internalization of the Media Ideal, Peer Social Comparison, and Body Dissatisfaction: Implications for the Tripartite Influence Model. Dev. Psychol. 2015, 51, 706-713. [CrossRef]

60. Tiggemann, M.; Miller, J. The Internet and Adolescent Girls' Weight Satisfaction and Drive for Thinness. Sex Roles 2010, 63, 79-90. [CrossRef]

61. Perloff, R.M. Social Media Effects on Young Women's Body Image Concerns: Theoretical Perspectives and an Agenda for Research. Sex Roles 2014, 71, 363-377. [CrossRef]

62. Ferguson, C.J.; Winegard, B.; Winegard, B.M. Who is the fairest one of all? How evolution guides peer and media influences on female body dissatisfaction. Rev. Gen. Psychol. 2011, 15, 11-28. [CrossRef]

63. Lee, S.Y. How do people compare themselves with others on social network sites?: The case of Facebook. Comput. Hum. Behav. 2014, 32, 253-260. [CrossRef]

64. McLean, S.A.; Paxton, S.J.; Wertheim, E.H.; Masters, J. Photoshopping the selfie: Self photo editing and photo investment are associated with body dissatisfaction in adolescent girls. Int. J. Eat. Disord. 2015, 48, 1132-1140.

65. Tiggemann, M.; Slater, A. NetTweens: The Internet and Body Image Concerns in Preteenage Girls. J. Early Adolesc. 2014, 34, 606-620. [CrossRef] 
66. Wardle, J.; Haase, A.M.; Steptoe, A. Body image and weight control in young adults: International comparisons in university students from 22 countries. Int. J. Obes. (Lond.) 2006, 30, 644-651. [CrossRef] [PubMed]

67. de Lauzon, B.; Romon, M.; Deschamps, V.; Lafay, L.; Borys, J.M.; Karlsson, J.; Ducimetière, P.; Charles, M.A. The ThreeFactor Eating Questionnaire-R18 is able to distinguish among different eating patterns in a general population. J. Nutr. 2004, 134, 2372-2380. [CrossRef]

68. Anschutz, D.J.; Van Strien, T.; Van De Ven, M.O.; Engels, R.C. Eating styles and energy intake in young women. Appetite 2009, 53, 119-122. [CrossRef] [PubMed]

69. Yokum, S.; Stice, E. Cognitive regulation of food craving: Effects of three cognitive reappraisal strategies on neural response to palatable foods. Int. J. Obes. (Lond.) 2013, 37, 1565-1570. [CrossRef] [PubMed]

70. Racine, S.E. Emotional ratings of high- and low-calorie food are differentially associated with cognitive restraint and dietary restriction. Appetite 2018, 121, 302-308. [CrossRef]

71. Brytek-Matera, A. Interaction between Vegetarian Versus Omnivorous Diet and Unhealthy Eating Patterns (Orthorexia Nervosa, Cognitive Restraint) and Body Mass Index in Adults. Nutrients 2020, 12, 646. [CrossRef]

72. Brytek-Matera, A. Restrained Eating and Vegan, Vegetarian and Omnivore Dietary Intakes. Nutrients 2020, 12, 2133. [CrossRef]

73. Beiseigel, J.M.; Nickols-Richardson, S.M. Cognitive eating restraint scores are associated with body fatness but not with other measures of dieting in women. Appetite 2004, 43, 47-53. [CrossRef] [PubMed]

74. Rigotti, N.A.; Neer, R.M.; Skates, S.J.; Herzog, D.B.; Nussbaum, S.R. The clinical course of osteoporosis in anorexia nervosa. A longitudinal study of cortical bone mass. JAMA 1991, 265, 1133-1138. [CrossRef] [PubMed]

75. Bilsborough, S.A.; Crowe, T.C. Low-carbohydrate diets: What are the potential short- and long-term health implications? Asia Pac. J. Clin. Nutr. 2003, 12, 396-404. [PubMed]

76. Neumark-Sztainer, D.; Sherwood, N.E.; Coller, T.; Hannan, P.J. Primary prevention of disordered eating among preadolescent girls: Feasibility and short-term effect of a community-based intervention. J. Am. Diet. Assoc. 2000, 100, 1466-1473. [CrossRef]

77. McVey, G.; Tweed, S.; Blackmore, E. Healthy Schools-Healthy Kids: A controlled evaluation of a comprehensive universal eating disorder prevention program. Body Image 2007, 4, 115-136. [CrossRef]

78. Taylor, C.B.; Bryson, S.; Luce, K.H.; Cunning, D.; Doyle, A.C.; Abascal, L.B.; Rockwell, R.; Dev, P.; Winzelberg, A.J.; Wilfley, D.E. Prevention of eating disorders in at-risk college-age women. Arch. Gen. Psychiatry 2006, 63, 881-888. [CrossRef]

79. Laramée, C.; Drapeau, V.; Valois, P.; Goulet, C.; Jacob, R.; Provencher, V.; Lamarche, B. Evaluation of a Theory-Based Intervention Aimed at Reducing Intention to Use Restrictive Dietary Behaviors Among Adolescent Female Athletes. J. Nutr. Educ. Behav. 2017, 49, 497-504.e491. [CrossRef] [PubMed]

80. Zabinski, M.F.; Calfas, K.J.; Gehrman, C.A.; Wilfley, D.E.; Sallis, J.F. Effects of a physical activity intervention on body image in university seniors: Project GRAD. Ann. Behav. Med. A Publ. Soc. Behav. Med. 2001, 23, 247-252. [CrossRef] 